\title{
Cultural immersion and compassionate care in a study abroad course: the Greek Connection
}

\author{
Muriel Larson
}

\begin{abstract}
Background: Madeleine Leininger, a nurse anthropologist and nurse theorist, recognized caring as essential in providing culturally congruent care, and that congruent culture care had not been adequately addressed in nursing education. To address this issue, The Greek Connection: Embracing Transcultural Caring in Ancient and Modern Greece (henceforth referred to as The Greek Connection), an innovative study abroad course offered to baccalaureate students from the USA, has helped students open their minds to the multiple factors that influence care. Students become acquainted with Leininger's Theory of Culture Care in a culture that is both similar and different from their own. The course progresses from learning broad generalizations to the specifics of culture and culture care with the recognition that compassionate care extends beyond our own country and culture.

Findings: While we may differ from each other in the specifics of care, we learned in Greece that we do not differ in the principle of giving care and being cared for. Students studying in Greece grew in their understanding of culturally competent, compassionate care. They stated that they were "changed" in Greece - not an easy phenomena to define, but a "heart change" that opened their eyes to the world around them and their place in "the global community".

Conclusions: The Greek Connection has offered American baccalaureate students an opportunity to apply Leininger's Theory of Culture Care in a culture other than their own, and thereby gain a greater appreciation of the importance of compassionate, culturally congruent healthcare in the world today. Caring is the essence of nursing and is essential for curing and healing. Without compassionate care, there can be no curing, and nurses can learn to care in culturally congruent and competent ways. Understanding the need for compassionate, culturally congruent healthcare has an essential place in both nursing education and nursing practice.
\end{abstract}

Keywords: Culture, Compassionate care, Congruent culture care, Leininger's theory of culture care, Sunrise enabler

\section{Findings}

In the mid-1950's Leininger [1], a prominent nurse anthropologist and nurse theorist, recognized and reported that care and culture were two phenomena in nursing, and I will add, health care, "that had not been formally and systematically studied" ([1], p. 32). Leininger recognized well-ahead of her time that the world was becoming a "global community". She projected that by the year 2010 all nurses would need to be prepared to provide culturally congruent care in this rapidly changing world. She developed the Theory of Culture Care Diversity and Universality, and later founded the Transcultural Nursing

Correspondence: muriel.larson@augie.edu

Department of Nursing Augustana College, Sioux Falls, SD 57197, USA
Society (TCNS) which now serves the nursing profession with chapters around the world.

\section{A brief history of The Greek Connection}

The Greek Connection has its roots in Sioux Falls, South Dakota. The author's initial exploration of Greece took place while a graduate student at Augustana College in Sioux Falls in 1995, 1998 and 1999, each time as a part of a classics course entitled The Greek Experience. The experiences in Greece stimulated the author to develop a similar, but different course for baccalaureate students from the US in Greece that would focus on transcultural caring. Subsequently, The Greek Connection has been offered every year from 2004-2013 with over 200 American students taking advantage of the opportunity to study in Greece. 


\section{Course objectives and goals}

The goals and objectives of this month of immersion are as follows:

Goal 1. To experience a culture immersion in Greece Objectives:

- Apply Leininger's Theory of Culture Care Diversity and Universality in a diverse cultural setting, using dialogue with key and general informants, on-site exploration and observation, and participate in structured class activities that highlight the theory.

- Describe the Greek culture through the lens of the Sunrise Enabler

- Reflect on one's own personal journey as a member of "the global community" [1].

Goal 2. To examine the historical connection between ancient and modern health care practices using Leininger's Theory of Culture Care Diversity and Universality with the Sunrise Enabler.
Objectives:

- Identify specific Greek contributions to health and healing through background research, readings, and visits to ancient sites.

- Compare and contrast modern and ancient healthcare practices in Greece and the United States,

- Gain an appreciation for the heritage that the ancient Greeks left to the Western World.

\section{The theory of culture care}

Student understanding of culture care begins with an overview of Leininger's Culture Care Theory. The central purpose is to discover, document, interpret and explain the predicted and multiple factors influencing and explaining care from a cultural holistic perspective ([1], p. 36).

The major premise of the Theory is that "there are differences and similarities in transcultural care knowledge and practices that can be discovered which will lead to the

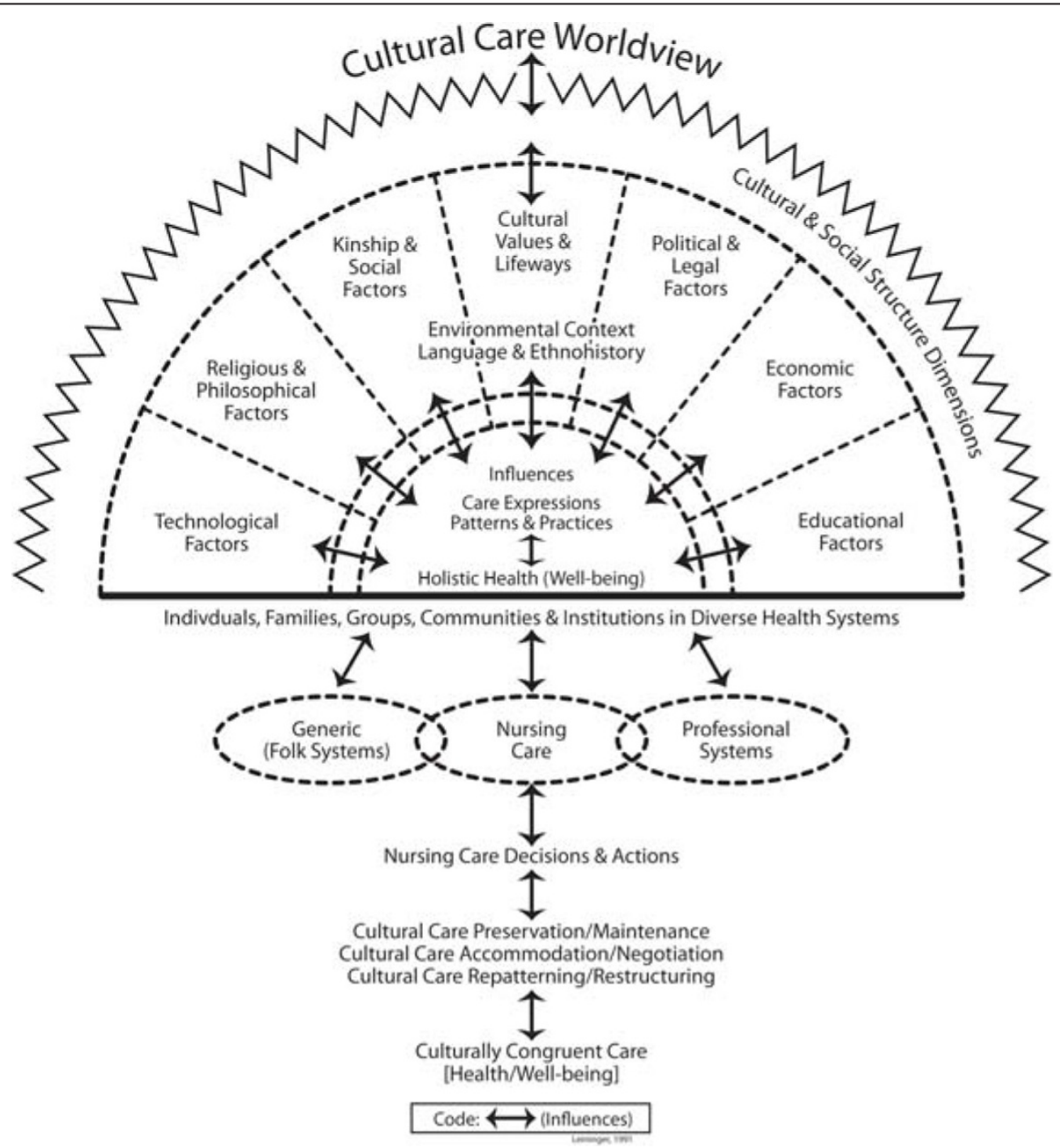

Figure 1 Leininger, M.M. (1997). Sunrise Enabler. Used with permission from Dr. Leininger [1]. 
establishment of a body of relevant transcultural nursing knowledge as a guide to nursing practice" ([1], p. 39).

The course objectives guided students in gaining cultural knowledge through the use of Leininger's Sunrise Enabler (Figure 1) and the following Cultural and Social Structural Dimensions: Technological Factors, Religious and Philosophical Factors, Kinship and Social Factors, Cultural Values and Lifeways, Political and Legal Factors, Economic Factors and Educational Factors. Students examine the similarities and differences in these factors and compare their findings to modern Greece and to the culture in the USA. They also learn about the historical connections of ancient Greece, and demonstrate through course assignments the significance of history in their understanding of health care practices, values, beliefs and practices, both ancient and modern.

The Sunrise Enabler is easy to remember visually as a rising sun. Leininger [1] used the sunrise image to remind nurses that "... the sun rise figuratively means to have nurses open their minds in order to discover the many different factors in influencing care." ([1], p. 40). This was an excellent image during the month of immersion, taking advantage of many beautiful sunsets in Greece.

The sunrise imagery in Leininger's theory led the author to explore using the art of photography to highlight the Cultural and Social Structure Dimensions. Ziller [2], gives a detailed account for the use of photography as a method for understanding, and proposes that values influenced by culture constitute an "iconic" form of communication. Photographic images form a language that is understood world-wide and Ziller maintains that photography has a place in a "visual record of individuals, groups, and societies, enhancing the understanding of culture and care". Photography provided a creative way of implementing Leininger's Sunrise Enabler for students in the course, and a technique for exploration using Leininger's Theory that was unique and memorable for the students as they captured Greek culture with their own photography.

Along with the Sunrise Enabler, students were introduced to other Enablers in Leininger's Theory. The Stranger-toTrusted Friend Enabler became a lived experience as they became immersed in the culture and developed friendships with the Greek people. The Observation-ParticipationReflection (OPR) Enabler was discussed and found to be helpful in their exploration, also [1].

Leininger's Sunrise Enabler provides students with a very useful tool for understanding the culture of Greece. While the Theory of Culture Care is directly applicable in transcultural nursing practice, The Greek Connection was offered to students of other disciplines. All of the students demonstrated excellent understanding of the theory and Sunrise Enabler, exploring the cultural factors that are common to all people. Through their participation and observations, they were able to get a comprehensive and holistic view of the Greek culture. "Each dimension of the Sunrise [Enabler] can be observed in Greece, both in terms of the present and the ancient culture. The observer juxtaposes past, present and future, and thereby participates in the rich traditions of Greece..." ([3], p. 5).

Through Leininger's work and wisdom, students recognized that compassionate care is the essence of health care, and is essential for well-being. Failure to be congruent with regard to beliefs and values results in cultural conflicts and added stress for individuals, families, and groups [4]. The Greek Connection encouraged students to learn about culture care, and then to apply their knowledge in a culture other than their own. The objectives and methods used in The Greek Connection are applicable in any culture, and could provide an exciting venue for understanding and embracing of compassionate care in our "global community".

Edward Markham's poem captures the heart and soul of the experience in Greece - giving and receiving compassionate care in a way that is reciprocal and beneficial to all involved in the relationship [5].

"There is a destiny that makes us brothers None walks his way alone, All that we give to the lives of others Comes back into our very own."

Competing interests

The author declares that she does not have any competing interests.

Authors' information

Muriel Larson, RN, MA

Assistant Professor, Emerita Augusta College, Sioux Falls, SD USA.

\section{Acknowledgements}

On behalf of myself and the over 200 students who traveled with me to Greece, our deepest thanks to the people of Greece who opened both their heart and culture to the students of The Greek Connection.

Received: 15 April 2014 Accepted: 23 October 2014

Published online: 01 December 2014

\section{References}

1. Leininger MM: Classic article: overview of the theory of culture care with the ethnonursing research method. J Transcult Nurs 1997, 8(2):32-52.

2. Ziller RC: Photographing the Self, Methods for Observing Personal Orientations. Newbury Park: Sage Press; 1990.

3. Larson M: The Greek connection: discovering cultural and social structure dimensions of the Greek culture using Leininger's sunrise model. ICUS Nursing Web Journal 2003(15).

4. Clarke PN, McFarland MR, Andrews MM, Leininger MM: Caring, some reflections on the impact of the culture care theory. Nurs Sci Q 2009, 22:233-239.

5. Markham E: (1852-1940), U.S. poet. A creed. In The Family Book of Best Loved Poems. Edited by George DL. Doubleday \& Company; 1952. 